PSI UNISC

Recebido em: 02/09/2019

Autor para contato: igor_psico@yahoo.com.br
ISSN: $2527-1288$

Aceito em: 24/01/2020

doi: $10.17058 /$ psiunisc.v4i1.14115

\title{
Problematizando as Práticas de Criminalização dos Movimentos Sociais: uma Análise Documental
}

Discutiendo Prácticas Criminalización de los Movimentos Sociales: un Análisis Documental

Discussing Practices Criminalization of Social Movements: an Analysis Documentary

Igor do Carmo Santos

ORCID: https://orcid/000-0002-6982-9971 Universidade Federal do Pará, Pará/Brasil

Flávia Cristina Silveira Lemos

ORCID: https://orcid.org/0000-0002-6601-0653 Universidade Federal do Pará, Pará/Brasil

Declaração de Direito Autoral

A submissão de originais para este periódico implica na transferência, pelos autores, dos direitos de publicação impressa e digital. Os direitos autorais para os artigos publicados são do autor, com direitos do periódico sobre a primeira publicação. Os autores somente poderão utilizar os mesmos resultados em outras publicações indicando claramente este periódico como o meio da publicação original. Em virtude de sermos um periódico de acesso aberto, permite-se o uso gratuito dos artigos em aplicações educacionais e científicas desde que citada a fonte conforme a licença CC-BY da Creative Commons.

\section{Resumo}

Este trabalho teve como objetivo fazer um levantamento, revisão e análise da literatura acerca do tema "Criminalização dos Movimentos Sociais". Foram utilizadas para a análise dissertações coletadas no ano de 2013 encontradas sobre esse tema no banco de dados da Biblioteca Digital Brasileira de Teses e Dissertações (BDTD). Para a análise das dissertações foram utilizadas as pistas deixadas pelo trabalho realizado por Michel Foucault através de suas ferramentas arqueológicas e genealógicas de análise que nos forneceu a possibilidade de uma crítica e uma problematização das práticas discursivas (saber) e não discursivas (poder e subjetivação) que atravessam e compõem os trabalhos analisados, guiado pela visão de uma história descontínua que deflagra acontecimentos em sua singularidade. Verificamos que as séries recortadas das dissertações trazem à mídia, a justiça, a polícia e o governo como principais elementos de uma prática de criminalização dos movimentos sociais, sem esquecerse de apontar as resistências promovidas por esses grupos contra esse processo.

Palavras-chaves: Criminalização; Movimentos Sociais; Cidadania; Biopoder; Foucault.

\section{Resumen}

Este estudio tuvo como objetivo de la encuesta, revisión y análisis de la literatura sobre el tema "La criminalización de los movimientos sociales". Se utilizaron para analizar los ensayos que se encuentran en este tema en la base de datos de la Biblioteca Digital Brasileña de Tesis y Disertaciones (BDTD) de 2013. Para el desarrollo del análisis de las disertaciones se utilizaron las pistas dejadas por el trabajo realizado por Michel Foucault a través de sus herramientas de análisis arqueológicos y genealógicas que proporcionan sobre la posibilidad de una crítica y el cuestionamiento de las prácticas discursivas (saber) y otros (de alimentación e subjetividad) cruce y recuperar el trabajo analizado, guiado por la visión de una historia discontinua que desencadena los acontecimientos en su singularidad. Encontramos que la serie de disertaciones cortó traer a los medios de comunicación, el poder judicial, 
la policía y el gobierno como elementos clave de una práctica de la criminalización de los movimientos sociales, sin olvidar señalar la resistencia promovida por estos grupos contra este proceso.

Palabras clave: Criminalización; Movimientos Sociales; Ciudadanía; biopoder; Foucault.

\begin{abstract}
This work had as the goal an analysis of a bibliographic survey and review about "Criminalization of Social Movements". Were used to analyze dissertations found about this subject in the database of the Brazilian Digital Library of Theses and Dissertations (BDTD), in 2013. For undertaking analysis of the dissertations were used the clues left by the work undertaken by Michel Foucault through his archaeological and genealogical tools of analysis provided us with the possibility of a critique and questioning of discursive practices (knowledge) and non-discursive (power and subjectivity) that cross and make the studies analyzed, guided by the vision of a discontinuous history that triggers events in its uniqueness. We note that the series of jagged dissertations bring to the media, the judiciary, the police and government as key elements of a practice of criminalization of social movements, not forgetting to point resistance promoted by these groups against this process.
\end{abstract}

Keywords: Criminalization; Social Movements; Citizenship; Biopower; Foucault.

\section{Introdução}

Esse artigo consistiu em uma pesquisa histórica e documental, com levantamento e revisão da literatura, apoiada em alguns elementos do método arqueogenealógico de Michel Foucault, quando da análise de algumas dissertações pesquisadas na Biblioteca Digital Brasileira de Teses e Dissertações (BDTD), no ano de 2013. Com isso, o início do presente texto tem o objetivo demonstrar os balizadores teóricos e metodológicos adotados nesse trabalho, assim como os procedimentos utilizados para a análise de algumas dissertações pesquisadas.

$O$ interesse na investigação sobre as práticas de criminalização dos movimentos sociais partiu do estabelecimento de alguns parâmetros para que pudesse ser viabilizado. Primeiro, a realização de um levantamento e revisão da literatura acerca da temática da criminalização dos movimentos sociais nas bases de dados dos periódicos da CAPES até o ano de 2013. Segundo, foi delimitada a circunscrição de a análise apenas de periódicos presentes na base SCIELO, por essa ser uma das principais na consulta de pesquisares(as), sendo um dos portais mais acessados e reconhecidos pela CAPES em termos do processo de seleção e esquadrinhamento da produção da verdade, na sociedade atual, sobretudo, no campo da política científica tal qual está organizada.

Em uma sociedade como a nossa, mas no fundo em qualquer sociedade, existem relações de poder múltiplas que atravessam, caracterizam e constituem o corpo social e que essas relações de poder não podem se dissociar, se estabelecer nem funcionar sem uma produção, uma acumulação, uma circulação e um funcionamento do discurso. Não há possibilidade de exercício do poder sem certa economia dos discursos de verdade que funcione segundo essa dupla exigência e a partir dela. Somos submetidos pelo poder à produção da verdade e só podemos exercê-lo através da produção da verdade (Foucault, 2012, p. 279).

Por essa razão, seria interessante analisar o que está em circulação nos jogos de saber e poder de formulação e difusão deste periódico a respeito do tema "movimentos sociais e o seu processo de criminalização". Sabe-se que esta pesquisa, sintetizada neste texto tem limites de tempo e espaço bem como 
da complexidade das problematizações possíveis de serem realizadas. Assim, de antemão, indica-se que estudos com esta temática e metodologia sejam ampliados e desenvolvidos por redes de pesquisas, especialmente, em contextos de recrudescimento da democracia participativa na América Latina, nos últimos anos. Ao realizar a pesquisa no portal SCIELO, em 2013 com a palavra-chave "criminalização dos movimentos sociais" obteve-se como resultado 16 artigos. No entanto, após a leitura dos resumos destes artigos, constatou-se que apenas seis desses artigos abordavam a questão da criminalização como objetivo principal do texto, enquanto o restante apenas citava esse processo como algo que permeava os movimentos sociais. Deste modo, na tentativa de encontrar outros materiais foram feitas novas pesquisas, no ano de 2013. Procurou-se na Biblioteca Digital Brasileira de Teses e Dissertações (BDTD). Nessa pesquisa teve-se o resultado de dez documentos, sendo 5 dissertações e 4 teses. Como esses trabalhos são resultados de uma intensa pesquisa, a qual geralmente leva um tempo de dois a quatro anos para ser desenvolvida (no caso das dissertações e teses, respectivamente) enquanto que os artigos geralmente são pequenos recortes de estudos ou, geralmente são trabalhos que não têm a mesma duração nem o mesmo cuidado teórico e metodológico, considera-se que a análise daqueles documentos contemplaria o objetivo deste trabalho. No entanto, com o período estabelecido para a realização do mesmo trabalho, optou-se por analisar as cinco dissertações encontradas no portal da CAPES, no ano de 2013.

Ressalta-se que a escolha da BDTD não interfere no nosso interesse inicial de fazermos a pesquisa em um banco de dados que fosse importante e relevante nesse processo de fazer circular regimes de verdade. Pois, essa biblioteca digital, reuni e integra os sistemas de informação de teses e dissertações existentes nas instituições de ensino e pesquisa brasileiras promovendo e dando visibilidade a essas publicações. Com isso, a escolha por essa base mantém o nosso critério de selecionar materiais que são classificados de reconhecida relevância, por fazer circular produções e trabalhos que passam por avaliações nas pósgraduações brasileiras, todavia, sabe-se dos limites e atravessamentos políticos presentes neste sistema de avaliação e na construção de plataformas e sistemas diversos de divulgação acadêmica. Observa-se que todo campo de discursos é marcado por lutas e embates, jogos variados e diversos, muitos deles resultantes de filtros e seleções arbitrárias e até mesmo demarcadas por interesses específicos de certa comunidade, no bojo da política científica. Deste modo, sair do conformismo e criar resistências também nas universidades quanto à dinâmica de silenciamentos dos lugares de fala dos movimentos sociais é uma atitude crítica e de extrema relevância, principalmente, no Brasil (Chauí, 1996; 2000).

Com efeito, é crucial pensar a história política da hierarquização da verdade do que tomar a noção de ciência imparcial e neutra. Em especial, quando se estuda os movimentos sociais é possível afirmar que há certa desqualificação no mundo cientificista, em determinados setores e enclaves academicistas. Para tanto, decidiu-se investigar as dissertações produzidas sobre esse tema, em 2013, no Brasil, a partir de recortes baseados em algumas séries discursivas que traziam regularidades sobre esses processos. Entendeuse que a investigação em documentos que tratam do tema da criminalização por si só já é uma atitude política de resistência às práticas de silenciamento universitário a respeito dos documentos produzidos e dos efeitos dos mesmos.

Dessa forma, o levantamento da literatura e as ferramentas metodológicas utilizadas pretendiam contribuir para essa discussão, não apenas por apresentarem como esse acontecimento "Criminalização dos Movimentos Sociais" vem aparecendo nos debates teóricos, mas também para que tivessem uma potência política de resistência às práticas criminalizadoras. Esse trabalho se propôs, portanto, a analisar as dissertações pesquisadas na Biblioteca Digital Brasileira de 
Teses e Dissertações (BDTD) sobre a temática da "Criminalização dos Movimentos Sociais", levantadas em 2013, a partir das ferramentas teórico-metodológicas de Michel Foucault, organizando e analisando as séries discursivas que apareceram de forma regular nos trabalhos levantados, a partir do referencial teórico já mencionado.

\section{A Prática da Criminalização dos Movimentos Sociais}

O processo de criminalização dos movimentos sociais, como um elemento que visa impedir que o exercício da cidadania ocorra de forma intensiva, se configura como um verdadeiro obstáculo à democracia participativa. Vivendo em uma "Era de Direitos", conforme fora colocado por Norberto Bobbio, é intrigante que aqueles grupos que se mobilizam na busca da promoção e garantia de direitos sofram processos que objetivam desqualificar, difamar e criminalizar suas ações. Sob esse aparente paradoxo que se apresenta dentro da realidade política brasileira, resolvemos nos debruçar nessa investigação das práticas discursivas e não discursivas que atravessam e constituem essas práticas de criminalização. É importante ressaltar que a maneira de ver, pensar e sentir a história tem se constituído em nas sociedades, sobretudo, a partir de uma visão teleológica. Nesta vertente, a visão do tempo é linear, nos fazendo recair em uma crença da história como uma seta de evolução para o futuro. E sobre essa maneira de se pensar e construir as narrativas historiográficas, inúmeras práticas criminalizadores, segregacionistas e higienistas têm se apoiado e se mantido dentro da sociedade como efeitos dos racismos de Estado e de sociedade na própria maneira de fazer ciência e divulgá-la. Ao problematizar as práticas que tornam possíveis a criminalização de determinados grupos e segmentos da sociedade brasileira era e é preciso, portanto, colocar em xeque um modo linear de fazer história.

$\begin{array}{cccc}\text { A história contada } & \text { pelos } & \text { chamados } \\ \text { vencedores, } & \text { estadistas } & \text { e } & \text { militares }\end{array}$

desconsiderada a relevância dos atos de movimentos sociais para a sociedade e para a própria produção científica. Geralmente, a História tradicional focava nos acontecimentos nacionalistas, liderados por burocratas e comitês de especialistas ou ainda por altas patentes das Forças Armadas (Certeau, 1979). As narrativas historiográficas a respeito dos movimentos sociais eram criminalizantes e desqualificadoras. Nos anos 1960, surge uma Nova História, o movimento dos Annales que passa a repensar o lugar dos classificados como vencidos. Assim, com efeito, a História Cultural passou a valorizar a história dos vencidos e não apenas valorizar a memória dos denominados vencedores pelos discursos oficiais. Era necessário reconhecer que os grupos de segmentos criminalizados não concordavam com o curso que a história tomava quando os movimentos sociais eram excluídos das narrativas como autores e não apenas passivos. Eles queriam promover lacunas, hiatos, rompimentos, subverter essa história que não os incluíam nos livros, que não dedicavam monumentos aos seus heróis, que não guardavam suas obras nos grandes museus, e que insistiam em dizer-lhes que não tinham história (Certeau, 1979).

Para tanto, considera-se pertinente utilizar as pistas teóricas e metodológicas deixadas por Foucault, quando estas nos fazem questionar e desnaturalizar os vários objetos do mundo. Ao empreender essa tarefa verificamos que esses objetos são atravessados por práticas de poder e saber que forjam esse objeto e o constituem com sentidos e significados que se não são historicizados, se cristalizam e tendem a se naturalizar, produzindo verdades acerca desse objeto. Considera-se que essa retomada da visão sobre a história e sobre a analítica de poder de Foucault, que foram os instrumentos fundamentais utilizados por esse autor para pensar a forma de como temos nos constituído como sujeitos dentro da história, tenham fornecido os instrumentos necessários para pensar a atualidade vivida. A necessidade de escrita desse trabalho se impõe por trazer à discussão uma temática de extrema importância para a democracia brasileira, pois, falar sobre 
movimentos sociais significa discutir as formas de participação da sociedade civil, através de sua organização, em coletivos que se pretendem potentes, na proposição e elaboração de políticas públicas que visem promover e garantir os inúmeros direitos conquistados através das lutas e mobilizações feitas por esses grupos.

A importância dos movimentos sociais e as suas formas de ação passaram a ser cada vez maiores dentro do cenário político nacional e mundial por algumas mudanças no contexto sociopolítico, econômico e cultural no Brasil e no Mundo. Gohn (2012) destaca alguns pontos fundamentais que favoreceram essas mudanças. Primeiro, podemos destacar a qualificação do movimento social como um tipo específico de ação coletiva, já que, na atualidade, a configuração dos novos movimentos se diferencia muito dos papéis que estes exerceram quando da sua aparição no cenário político mundial durante a passagem do séc. XIX ao XX (com o movimento operário e os movimentos revolucionários desde a Revolução Francesa) como daqueles movimentos que emergiram nos Estados Unidos nos anos de 1960 (direitos civis, feminismo, estudantil, etc.). A principal mudança dos novos movimentos reside na mudança de um olhar universal para um mais particular, o que significa dizer que, se antes os movimentos lutavam pelo "direito a ter direitos", hoje, eles lutam por interesses imediatos, os direitos de determinada categoria ou grupo social. Diani $(1992 ; 1997)$ aposta na noção de base e construção coletiva dos movimentos sociais, definem a dinâmica de (re)existência permanente destas organizações participativas e destes coletivos solidários e cooperativos na busca do bem comum, articulados por uma mobilização constante e pela densidade política de cada ato realizado, instituindo até mesmo uma pedagogia da emancipação e uma virada epistemológica nos universos estanques do cientificismo tradicional, pois são portadores de novos valores e apontam para outras táticas de educação, mais populares e menos rígidas do que as escolarizadas, todavia, não menos importante e incisiva na proliferação de efeitos positivos que produz no plano da transformação social.

Outro ponto se refere às relações entre os vários sujeitos sociopolíticos que compõem uma sociedade marcada por uma "globalização" econômica e cultural (Harvey et al., 2012). Essas relações são marcadas por uma ampliação dos sujeitos no protagonismo das ações coletivas, nas formas de mobilização (de cima para baixo) e nas formas de atuação (em redes); um terceiro ponto é demarcado pelas mudanças no papel do Estado nas suas relações com a sociedade civil e em seu próprio interior fundadas em contradições que permitem por um lado, a promoção da inclusão através de políticas voltadas a setores tidos como "vulneráveis" e "excluídos", ao mesmo tempo em que captura esses sujeitos em estruturas políticas na busca de maior coesão e controle social; o último ponto são as várias lacunas que ainda existem dentro do âmbito acadêmico a respeito dos movimentos sociais, pois apesar de sua presença marcante e de sua fundamental importância dentro do espaço sociopolítico ainda existem muitas dúvidas acerca do papel dos movimentos sociais na sociedade (Gohn, 2001; 2010).

\section{Análises e Artesanias}

Essa terceira parte do artigo se dedica a análise das dissertações encontradas, em 2013, dentro da Biblioteca Digital Brasileira de Teses e Dissertações (BDTD) que versam sobre o tema "Criminalização dos Movimentos Sociais". Entende-se quanto a análise desses documentos se mostra importante por duas razões principais: a primeira é que essas dissertações fornecem pistas do que está se produzindo no meio acadêmico a respeito desse tema, demonstrando quais saberes têm produzidos enunciados acerca e como os tem forjado? A segunda razão é política, no sentido de que, ao abordar essas temáticas, as dissertações colocam em evidência esse processo de criminalização e fazem com que novas formas de enfrentamento e busca de soluções sejam encontradas. Com isso, as 
análises empreendidas irão partir do destaque de alguns temas que aparecem com mais frequência dentro desses trabalhos. Buscou-se encontrar séries que apresentassem determinadas regularidades discursivas que ajudasse a construir e problematizar as práticas de criminalizações voltadas aos movimentos sociais. Como essas regularidades partiram de diferentes lugares institucionais ocupados por cada campo de produção de saber dessas dissertações e, assim, apresenta-se um resumo das seis dissertações analisadas para uma melhor visualização das posições assumidas por cada estudo diante dessas práticas. Vejamos a seguir:

\section{1) O Direito Humano Fundamental: a Reforma Agrária. Ana Paula Gularte Liberato, Direito, PUC-PR, 2003}

A autora do presente trabalho buscou analisar a reforma agrária enquanto um direito humano fundamental, e para isso, utilizou-se da evolução e caracterização da propriedade agrária brasileira a fim de justificar essa interpretação. Ao trazer esse histórico, a autora demonstra como a luta pelo direito à terra foi constante e um dos mais complexos a serem debatidos pela sociedade na tentativa de implementar uma verdadeira Reforma Agrária que possibilitasse o exercício efetivo da função social da terra/propriedade. No âmbito jurídico, foi com a Constituição Brasileira de 1988 em seu Art. 184 que fixou concretamente a Reforma Agrária como Direito Fundamental. Nesse contexto que aparecem grupos e movimentos que visam efetivar esse direito garantido pela Carta Magna, com destaque para o Movimento dos Trabalhadores Rurais SemTerra (MST), que se torna uma das mais importantes vozes de reivindicação pela Reforma Agrária. Com isso, a autora destaca para um fenômeno que passou a emergir sobre esses movimentos, atuando de forma a tentar deslegitimar as suas atuações através de um processo de criminalização. Esse processo, segundo a autora, é derivado de um choque entre diferentes visões colocadas pela Constituição de 88, vinculada a um Estado Democrático de Direito sensível à realidade social e ao Código Civil de 1916 que se enquadram na lógica de um Estado Liberal que defende a propriedade e seu possuidor. Ao fim, a autora conclui que o fato da Carta Magna passar a proteger a sociedade através da regulamentação dos interesses coletivos e difusos, tornou esses direitos indivisíveis, intangíveis e inalienáveis, caracterizados como cláusulas pétreas, e, portanto, estando no rol dos direitos fundamentais. Assim, posto que a reforma agrária é direito fundamental, os movimentos sociais agrários são legítimos e impassíveis de sofrerem qualquer tipo de criminalização.

\section{2) A Construção da Criminalização no} Jornal: Uma Abordagem Discursiva. Beatriz, Sánchez, Letras, 2006, UERJ

Nesse trabalho, a autora se propôs a explicitar os processos de construção da imagem discursiva tanto dos atores sociais envolvidos (o criminoso e a vítima) quanto do objeto-de-discurso "delito" em matérias informativas de jornais de edição diária de grande circulação do Estado do Rio de Janeiro, sob a perspectiva da Análise do Discurso guiada pela visão discursiva. Para realizar tal empreendimento, a autora utilizou-se de três tipologias delituosas: roubo, estelionato e colarinho branco. $\mathrm{O}$ arcabouço teórico utilizado foi a Análise do Discurso orientada pelo dialogismo bakhtiniano que se opõe a uma visão que considera a matéria informativa isenta das marcas da subjetividade. Esse trabalho propõe um diálogo com a visão de alguns criminólogos que se alinham dentro do movimento denominado Criminologia Crítica que discutem como os meios de comunicação manipulam a informação de forma a (re)produzir a violência dentro da sociedade. A análise incluiu a identificação das designações, dos processos qualificativos e das vozes trazidas pelo enunciador-jornalista e que atravessam e organizam a matéria informativa. Dessas categorias operacionais a autora depreendeu posições discursivas que dizem respeito ao jornalista que (re)constrói discursivamente aqueles delitos. Como conclusão a autora coloca em questão a noção 
de objetividade e evidencia o tratamento enunciativo diferencial dos ilegalismos analisados de acordo com as desigualdades sociais.

A Criminologia Crítica assinala para a dimensão de uma luta com o Direito para além das leis e da noção de justiça limitada ao Direito Penal e ao Sistema de Justiça Criminal, pois, invocar os direitos humanos para criminalizar em nome da proteção e da defesa social é provocar um conjunto de processos de judicialização intensivos em nome da vingança e pouco efetivos na transformação social (Wacquant, 2003).

3) Aqueles que vivem nas margens, às margens da decisão: controvérsias sobre o uso dos rios e das terras ribeirinhas para geração hidrelétrica. Francisco Hernández, Energia, 2006, USP

A ideia principal do autor neste trabalho é a de "destituição da fala" de grupos sociais, indígenas, camponeses, ribeirinhos, ameaçados e atingidos por barragens e grupos da sociedade organizada como os sindicatos que representam os trabalhadores das empresas elétricas e organizações não governamentais que discordam da maneira como vem se conduzindo o processo de expansão da oferta de eletricidade através da construção de hidrelétricas. Para demonstrar isso o autor faz um pequeno retrospecto das lutas sociais por democracia nos últimos 30 anos e um histórico da consolidação das empresas elétricas, vinculando-o com a história política brasileira e as relações entre interesses privados e ações do governo. O que se verificou foi uma baixa participação dos grupos sociais nas decisões tomadas no que concerne aos projetos hidrelétricos. $\mathrm{O}$ autor conclui o trabalho apontando algumas possibilidades de enfrentamento político desses grupos sociais.

\section{4) “Protestar não é delito”. A criminalização dos movimentos sociais na Argentina contemporânea - o caso do movimento piquetero (1997-2007). Fernanda Soares Cardoso, 2008, UFRG}

Esse trabalho teve como objetivo desenvolver uma análise dos diversos significados construídos sobre a ação dos movimentos piqueteros na Argentina, no período de 1997 a 2007, além de estabelecer relações entre estes movimentos e a ação dos governos que foram estabelecidos durante o período proposto. A partir disso, a autora defendeu a tese de que a atuação do governo argentino, legitimada e apoiada pelos meios de comunicação do país, criou um contexto de criminalização dos movimentos sociais, em especial o movimento piquetero. Foram privilegiados dois eixos de análise: as diferentes formas que a repressão assumiu durante os governos desse período mencionado, assim como as relações que se estabelecem entre o movimento piquetero e o peronismo; e a avaliação de políticas como a elaboração de uma legislação específica que enquadrasse os atos de protesto como delitivos e regulasse o acesso e utilização dos locais públicos e a criação de um polícia especialmente treinada para atuar junto aos piqueteros, considerando seus efeitos de acirramento ou diminuição dos conflitos.

\section{5) Ciberativismo e MST: o debate sobre a Reforma Agrária na nova esfera pública interconectada. Lucas Milhomens Fonseca, Comunicação, 2009, UFPB}

Essa pesquisa buscou analisar os novos elementos midiáticos e digitais advindos da internet e das Novas Tecnologias de Informação e Comunicação (NTICs). O autor verificou como a cibercultura, ou o ciberativismo é utilizado pelo Movimento dos Trabalhadores Sem-Terra (MST). Assim, demonstrou como esse movimento social (considerado o maior do país e um dos maiores do mundo) se apropria desses novos recursos para promover e divulgar a sua militância e propaganda ideológica dentro e fora desse ciberespaço.

Analisamos as formas de atuação política, social e cultural exercidas pelo MST na rede mundial de computadores através do sítio do Movimento (www.mst.org.br) e todos 
os seus recursos e ferramentas interativas. O autor conseguiu verificar que o MST chegou a um novo patamar da luta pela Reforma Agrária, através da ampliação do debate e aprofundamento democrático do que ele chamou de Nova Esfera Pública Interconectada, o que propicia criar um ambiente de contraposição aos veículos tradicionais de imprensa, indo de encontro a Grande Mídia e sua incessante criminalização dos movimentos sociais. Benford (1997) e Benford e Snow (2000) assinalam o quanto há um jogo de interpretações e enquadramentos diversos na maneira de realizar apropriações dos valores e discursos no bojo das lutas cotidianas de movimentos sociais face às narrativas de corporações do grande capital nacional e internacional.

\section{Análises das Dissertações: Deslocamentos e Dinâmicas}

Neste item, é importante trazer as séries discursivas que foram selecionadas e recortadas nas dissertações apresentadas acima. Podemos observar que essas dissertações são provenientes de campos de saberes distintos, mas que apesar disso, conseguem trazer determinadas regularidades que nos permitem enxergar os vários atravessamentos que compõem e formam as práticas de criminalização. Os vários discursos perpetrados nessas dissertações se cruzam e são imanentes fazendo com que o estudo dessas práticas não se limite a uma única disciplina ou campo de saber. Nesse sentido, buscou-se justamente destacar as regularidades que atravessam esses regimes de forma que fosse possível realizar uma análise delas.

\section{a) Mídia}

Um tema presente em quase todas as dissertações analisadas foi a mídia e as suas diversas formas de transmitir notícias que levavam a um processo de criminalização. Isso não acontece por acaso, vivemos hoje em uma época regida sob a égide da informação. A todo o momento nos deparamos e nos confrontamos com informações provenientes de grandes e pequenas mídias. Somos literalmente sufocados diante de tantas notícias, informações, propagadas por veículos como televisão, rádio, internet expressas diariamente por reportagens, manchetes, propagandas, que transmitem mensagens com as quais, na maioria das vezes, não conseguimos dialogar e acabamos, por assim dizer, nos sujeitando a essas informações e nos transformando em indivíduos, como diria Guattari e Rolnik (2005).

Em um diálogo com esses autores, percebe-se que a mídia, como um importante agente transmissor de "cultura" da sociedade, faz parte do que é chamado de "modos de produção capitalísticos" que se caracterizam não apenas por um funcionamento exclusivo no "registro dos valores de troca, valores que são da ordem do capital, das semióticas monetárias ou dos modos de financiamento. Eles funcionam também através de um modo de controle da subjetivação" (Guattari \& Rolnik, 2005, p. 21). É o que eles vão chamar de "cultura de equivalência", pois vai ocorrer uma equivalência entre o capital e a cultura de forma que estes vão agir de forma complementar, no qual, o primeiro vai agir sobre a sujeição econômica, e o segundo, na sujeição subjetiva.

Essa sujeição subjetiva é tão intensa que, por exemplo, Guareschi (2006) destaca que nos países ocidentais as pessoas adultas assistem em média em torno de vinte e cinco a trinta horas as suas televisões, e isso sem falar no tempo gasto escutando rádio ou música estereofônica, lendo jornais, livros e revistas e durante o consumo de outros produtos das grandes indústrias de comunicação de larga escala e transnacionais. Em outras palavras, tudo isso significa dizer que é praticamente impossível nos constituir como sujeitos hoje sem estabelecer alguma relação com a mídia, tal qual a sua ubiquidade dentro da nossa sociedade. É por essa razão que esse tema aparece de forma tão recorrente durante as práticas que promovem a criminalização dos movimentos sociais, pois a mídia aparece como um dispositivo que cria, forja, elabora imagens cotidianas das lutas e movimentos a partir de 
olhares que não são universais, mas se pretendem universalizantes.

Contudo, há contra narrativas de outras mídias, mesmos que menores e denominadas de imprensa nanica podem produzir barulho e deslocarem discursos (Avritzer, 2013). Os movimentos sociais têm conseguido criar outras maneiras de dar visibilidade para os ativismos mundialmente, em redes quentes de resistência aos discursos oficiais dos grandes oligopólios de informação. É cada vez mais urgente pensar formas de democratizar as mídias brasileiras e resolver os impasses que as atravessam e balizam em estratégias elitistas e limitadas aos interesses de poucas corporações e grupos. E, dessa forma, por exemplo, que Lemos e Cardoso (2008) aponta a atuação dos meios de comunicação argentinos ao tratar do movimento piquetero que atua naquele país. Segundo a autora, as estratégias utilizadas por esses vários veículos,

Vão desde a banalização dos protestos, reiterando sua frequência; deslegitimação de suas reivindicações e do recebimento de assistência estatal; o papel de ser porta-voz da versão oficial, como no caso de Avallaneda e no reforço a política de cooptação e isolamento de determinados grupos; e a própria criminalização através da criação de uma imagem de violência, embate e periculosidade. (Cardoso, 2008, p. 78).

Com isso, vai se criando uma imagem "oficial" de um movimento social a partir do olhar de uma entidade que estaria acima dos outros poderes do Estado. O "quarto poder", como se autodenomina a imprensa, teria como missão realizar a vigilância dos poderes executivo, legislativo e judiciário, na incumbência de denunciar possíveis excessos cometidos por tais poderes. Assim, a mídia construiu uma imagem de defensora do interesse público, difusora de informações e notícias objetivas, pautada numa cobertura dos "fatos" de forma absolutamente imparcial. Um olhar mais crítico dessa situação permite-nos enxergar que a notícia do fato por si só guarda uma intenção, ela busca levar a determinados efeitos de verdade, não a partir da intenção de um grupo maquiavélico que busca "dominar o mundo", mas a partir de práticas datadas, localizadas e provenientes de diversos grupos e interesses sociais, políticos e econômicos.

É isso que permite Guareschi (2006) afirmar que os meios de comunicação constroem realidades, ou seja, eles ajudam a produzir subjetividades que enxergam, sentem e valoram o mundo a partir de uma ótica. Mais do que isso, a realidade é aquilo que é veiculado através dos meios de comunicação, pois aquilo que não se encontra na mídia, não existe, seria tomado como irreal. É assim que cotidianamente não é possível enxergar como determinadas lutas e certas existências vivem. Opera-se a fabricação de muitos grupos e modos de vida enquanto invisíveis, como os próprios movimentos sociais. Muitas vezes, presencia-se determinadas falas que questionam o desaparecimento de certas pautas de luta como se não existissem mais ou tivessem feito parte da história e hoje se encontrassem apenas nos registros da memória. Isso leva a uma segunda afirmativa em relação à mídia: ela não somente diz o que existe e, consequentemente, o que não existe, mas atribui determinados valores a essas existências. Aquilo que aparece e que é veiculado nas mídias, é visto como bom, pois é digno de que seja transmitido, que seja (re)conhecido.

Já aquilo que não passa nas mídias é indigno, apenas merece registro se for pela via da infâmia, como nos coloca Foucault. Atrelado a isso, em uma terceira afirmação aparece: a mídia dita a agenda de discussão. Se vamos discutir sobre o tráfico de escravos (por coincidência um acontecimento que está atingindo um famoso personagem de uma novela de grande sucesso) ou sobre quem vai ganhar o Big Brother Brasil é decorrente de um jogo midiático que coloca em debate para a sociedade determinadas questões. 
Tudo isso põe em xeque a ética e transparência pública da e na mídia. E não é à toa que isso acontece. Segundo Castro (2012), existe um controle da mídia por verdadeiros conglomerados globais, os quais monopolizam a informação dentro de uma economia globalizada. $\mathrm{O}$ autor menciona $\mathrm{o}$ caso brasileiro, onde aponta que existem no Brasil 9.477 veículos de informação, sendo que apenas uma minoria produz um conteúdo independente enquanto que a maioria se vincula em redes com outros veículos. Apesar de economicamente e tecnicamente a formação de redes ser algo vantajoso, pois com isso se reduz gastos em termos de produção e ainda ocorrer um benefício da operação de marketing dos grandes grupos nacionais, como a Globo, Record, SBT e Band, isso faz com que esses grandes grupos dominem o mercado $\mathrm{e}$ produzam o conteúdo que será veiculado pela maioria dos outros veículos locais, o que evita uma regionalização das programações e impede a singularização das notícias.

Esse controle é que permite aos veículos de comunicação no Brasil e no mundo o domínio social e cultural, diminuindo o plano de circulação das notícias e acontecimentos de uma forma mais democrática como se espera e como é previsto na Constituição Federal de 1988, à qual proíbe a formação de monopólio e oligopólio dos meios de comunicação no território brasileiro. No entanto, na prática o que se assiste é o domínio da programação por essas grandes empresas que ditam, por exemplo, que o brasileiro prefere supostamente um "bom" entretenimento à educação e cultura na grade televisiva. Fonseca (2009) aponta que:

A grande mídia brasileira sempre atuou contrariamente às movimentações progressistas de vários setores da sociedade. Foi assim durante todo o período da ditadura militar, quando em um dos momentos de maior perseguição às liberdades civis, com torturas e desaparecimentos de cidadãos envolvidos (ou não) com a oposição ao regime, que em 1972 o então presidente militar Emílio
Garrastazu Médici disse, referindo-se à empresa televisiva que viria a ser o maior sistema de comunicação do País que "se sentia feliz todas as noites quando assistia o noticiário, porque na TV Globo o mundo estava um caos, mas o Brasil estava em paz, era como tomar um calmante após um dia de trabalho" (p. 44).

O jornal como um veículo de transmissão e invenção de informações acaba por orientar a formação de subjetividades, já que modifica a maneira de se perceber o delito, fortalecendo um dualismo maniqueísta, em que se justificam medidas, às quais, supostamente venham exterminar o que se define enquanto mal, realizando um jogo de visibilidade e invisibilidade dos componentes sociais, econômicos e políticos das tensões em uma rede de intrigas e interesses em disputa. No Brasil, Branford e Rocha (2004) citado por Fonseca (2009), explicitam como essa criação de um lado "mal" que deve ser aniquilado é construído e apontam algumas razões:

No Brasil, em particular, a "fabricação do esquecimento" é feita com desenvoltura muito maior do que a encontrada em boa parte dos países europeus e Estados Unidos. A razão é simples: dados a extrema desigualdade social, o imenso número de analfabetos e a desorganização política da sociedade civil, a elite sempre foi capaz de, confortavelmente, contar ao seu modo a história do País [...] Por essas e outras os movimentos populares e organizações de esquerda raramente conseguiram emplacar jornais de grande tiragem, e menos ainda diários. Em outros termos, no Brasil, talvez mais do que qualquer outro grande país ocidental, o monopólio da narrativa histórica sempre foi exercido pelas elites. No Brasil contemporâneo, a cobertura das ações do Movimento dos Trabalhadores Rurais Sem-Terra é a mais pura, clara e nítida expressão 
dessa história. O MST é total e abertamente demonizado pelos maiores veículos de imprensa escrita, televisionada e radiofônica (Branford \& Rocha, 2004 citado por Fonseca, 2009, p. 45).

O mesmo autor destaca como o Movimento dos Trabalhadores Rurais SemTerra (MST) vem sendo atacado por determinados veículos midiáticos de forma intensa no Sudeste do País, como por exemplo, o jornal "O Estado de São Paulo" e, principalmente, a revista "Veja", da Editora Abril. Esta última se destaca pelo fato de ser a revista semanal de maior tiragem no País e por representar os interesses de uma classe historicamente contrária à reforma agrária, estando muitos de seus proprietários ligados ao agronegócio. A intensidade da criminalização processada pela revista contra o MST ocorre de forma tão intensa que Fonseca (2009) destaca que no período de janeiro a setembro de 2009, foram publicadas 11 matérias com referências ao movimento nesta revista, e apenas nos meses de junho e julho não tiveram registros sobre o MST.

E, essas matérias quase sempre vinculam o MST a um movimento de vândalos, arruaceiros, baderneiros ou ligados a atitudes delituosas. Alguns títulos das matérias exemplificam a forma como um movimento é abordado pela revista: "O Manual da Guerrilha"; "Os inimigos da Vale"; "Eles invadem e também matam"; "Bolsa-Baderna"; "Em defesa do direito à propriedade"; "Indiciados pela polícia de Pernambuco seis integrantes do MST"; "Por dentro do Cofre do MST"; "Uma CPI para investigar o MST" (Fonseca, 2009).

Verifica-se que o fator "mídia" aparece como uma regularidade nos documentos analisados por ser um dispositivo que permite circular determinadas verdades que afetam e geram efeitos políticos determinantes para um processo de criminalização. Tomar o MST, o movimento piquetero e inúmeros outros existentes no país como vândalos, baderneiros, rebeldes sem causa, quadrilhas, é resultado desse jogo de poder que desqualifica determinadas lutas, objetiva e subjetiva esses movimentos a partir desses adjetivos. Não se quer negar que possam ocorrer práticas perpetradas pelos movimentos, às quais se encaixem nessas qualificações atribuídas aos mesmos, apenas busca-se ressaltar esse jogo em que uma mídia controlada por determinados setores sociais e políticos trava uma guerra com movimentos, os quais lutam pela garantia de determinados direitos, fazendo com que as práticas desses últimos sejam naturalizadas e permaneçam na regularidade das relações de poder em um quadro no qual a grande mídia "dá as cartas".

\section{b) Criminalizar e Judicializar}

Uma das regularidades mais presentes dentro das dissertações foram as práticas de criminalização e judicialização dos movimentos. O que seriam esses processos? Leão (2008) pontua que não se encontra facilmente uma definição do termo "criminalização" nos dicionários brasileiros. Geralmente se associa a esse termo o ato de criminalizar, e a esse verbo, dá-se o significado de "tornar criminal", ou seja, imputar-se um crime previsto na legislação penal à determinada conduta. José Murilo de Carvalho (2013) salienta o quando muitos grupos sociais no Brasil ainda permanecem à margem da cidadania e são duplamente punidos, primeiro por não terem direitos garantidos e, segundo, por serem alvo de intensa criminalização, apenas pelo fato de continuarem a lutar, como é o caso do Movimento Sem Terra.

A judicialização seria um desdobramento desse processo, já que o enquadre de determinada prática em uma lei penal faz com que esta caía nas malhas da justiça. Esse processo também é resultado de um fortalecimento das cortes constitucionais, os quais criaram novas instâncias de defesa do direito da cidadania e ampliaram os direitos assegurados pela constituição, e a sobreposição do Judiciário em relação ao Legislativo e Executivo como principal árbitro do conflito 
social (Sorj, 2004). Esses processos se caracterizam por serem os mais frequentes no impedimento das ações de lutas pelos direitos reivindicados por meio dos diversos movimentos sociais. Lemos e Cardoso (2008), por exemplo, ressalta que são essas práticas que têm sido cruciais na determinação do fenômeno da criminalização dos movimentos sociais. Isso acarreta em um intenso controle penal sobre a ação política, a mesma autora aponta que em uma análise das sentenças judiciais das cortes argentinas mostrou-se que há diversos atentados por parte dos juízes no sentido de negar diversos direitos constitucionais, tais como: a liberdade de expressão, o direito de reunião, associação e uso do espaço público, além de outras infrações aos direitos básicos. Há uma mutação do Direito na sociedade contemporânea, em uma escalada que iria dos direitos de primeira geração (direitos civis), de segunda geração (direitos políticos), de terceira geração (direitos sociais) e os chamados direitos coletivos e difusos, que teriam um caráter genérico, mas que abarcariam em si os direitos individuais e coletivos fundamentais de forma integrada. Pautada nessa mudança, a autora demonstra como a Reforma Agrária hoje estaria colocada como um direito fundamental, amparado por um Estado Democrático de Direito que busca resguardar todos os direitos inerentes à dignidade da pessoa humana.

No entanto, sabe-se que apesar da positivação desses direitos em importantes cartas e declarações, às quais versam sobre os principais direitos do homem, ainda assim vêse grande parte da população sem a garantia efetiva desses direitos. A própria Reforma Agrária, direito sobre o qual a autora mencionada discute e traz como um direito fundamental existe apenas no papel. Isso acontece devido a não problematização e historicização dos "direitos humanos" à terra. Como aponta Coimbra, Lobo e Nascimento (2008), os fundamentos dos chamados direitos humanos são provenientes de valores e ideais das conquistas provenientes da ascensão burguesa no período da Revolução Francesa (com os lemas igualdade, liberdade e fraternidade). Com isso, o capitalismo teria naturalizado esses valores, assinalando-os como direitos inalienáveis de uma ideia da essência do que é ser homem. Esse caráter burguês presente nas grandes declarações marcou desde esse período quais são os direitos enquadrados como os "mais importantes" e pelos quais se justifica lutar. É assim que, um dos direitos mais defendidos:

em nosso mundo, considerado sagrado é o direito à propriedade, garantido apenas para os que possuem. Os direitos humanos, portanto, têm apontado quais são esses direitos e para quem eles devem ser concedidos.

Ou seja, se tomados em sua perspectiva histórica, tanto o humano como os direitos são construções das práticas sociais em determinados momentos, que produzem continuamente esses objetos, subjetividades e saberes sobre eles. (Coimbra, Lobo, \& Nascimento, 2008, p. 92).

É esse olhar naturalizante que se coloca sobre os direitos que permite, por exemplo, a criminalização e judicialização dos protestos e dos movimentos sociais. Como nos exemplifica Cardoso (2008), um estudo da análise das sentenças judiciais na Argentina mostram que neles "há diversos atentados por parte dos juízes no sentido de negar direitos constitucionais como a liberdade de expressão, o direito de reunião, associação e de uso do espaço público, de petição às autoridades, além de diversas infrações a princípios básicos do direito" (p. 76). Esses direitos "negligenciados" pelos juízes são sobrepostos a outros que são colocados em primeiro plano, como menciona a mesma autora, destacando que um dos argumentos que aparecem com bastante frequência nas sentenças analisadas é a de que "há um choque de direitos ou de que todos os direitos têm um limite ("meu direito termina onde começa o do outro"), sem definir qual é o direito que se perde e qual o que se mantém. O direito de expressão é colocado em segundo 
plano, em detrimento do direito de circulação" (Cardoso, 2008, p. 77). Esses exemplos só corroboram a afirmação de Deleuze que, segundo Coimbra et al. (2008), os direitos humanos têm servido para criar uma ilusão de participação dos subalternizados, de que as classes abastadas preocupam-se com o bemestar dos mais pobres, de que o humanismo dentro do capitalismo é algo concreto, e a de que a máxima "todos os homens nascem livres e iguais em dignidade e direitos" é verdadeira. Contudo, Coimbra et al. (2008) ressalta que:

Os marginalizados de toda ordem nunca fizeram parte desse grupo que, ao longo dos séculos XIX, XX e XXI, tiveram e continuam tendo sua humanidade e seus direitos garantidos. $\mathrm{Ou}$ seja, foram e continuam sendo defendidos certos tipos de direitos, dentro de certos modelos, que terão que estar e caber dentro de certos territórios bem marcados e delimitados e dentro de certos parâmetros que não poderão ser ultrapassados. (p. 92).

É nesse ponto que se institui a norma, aquela que delimita, esquadrinha, circunscreve o corpo e uma população a determinados espaços e não permite que daí se escape. É, como foi pensado anteriormente, a sociedade de normalização aparece como uma "sociedade em que se cruzam, conforme uma articulação ortogonal, a arma da disciplina e a norma da regulamentação" (Foucault, 1999, p. 302). É preciso disciplinar os corpos e regulamentar a população para que se promova a vida, mesmo que para isso seja preciso e válido matar nos projetos de defesa social de burocratas de grandes corporações e do Estado constituído pelo terror em nome da segurança e governabilidade sob a égide dos racismos de toda sorte. Aniquilar a vida, a doença, os defeitos e os acidentes se torna necessário, e um Estado de sítio e urgência de cunho autoritário, em uma sociedade ávida por segurança, à qual abomina tudo aquilo que escape à norma (Carvalho, 2013).

\section{c) Práticas de Resistência}

É interessante observar que, apesar das duas análises anteriores apontarem o caráter perverso de alguns dispositivos que buscam sufocar e calar os movimentos, os documentos apontam para as resistências que têm se produzido pelos coletivos na tentativa de fortalecer a positividade de suas lutas e divulgar as reivindicações e práticas empreendidas por eles. É interessante perceber como isso está diretamente relacionado ao que Foucault (2010) aponta como sendo característicos das relações de poder-saber, pois como ele diz:

No centro das relações de poder e como condição permanente de sua existência, há uma "insubmissão" e liberdades essencialmente renitentes, não há relação de poder sem resistência, sem escapatória ou fuga, sem volta eventual; toda relação de poder implica, então, pelo menos de modo virtual, uma estratégia de luta, sem que para tanto venham a se superpor, a perder sua especificidade e finalmente a se confundir. Cada uma constitui para a outra uma espécie de limite permanente, de ponto de inversão possível. Uma relação de confronto encontra seu termo, seu momento final (e a vitória de um dos dois adversários) quando o jogo das relações antagônicas é substituído por mecanismos estáveis pelos quais um dentre eles pode conduzir de maneira bastante constante e com suficiente certeza a conduta dos outros (p. 294).

É assim que, por exemplo, diversos movimentos vêm se apropriando de mídias digitais e utilizando essas como ferramentas políticas no que se convencionou chamar de ciberativismo. Segundo Fonseca (2009), esse é um conceito recente em nossa sociedade, é acompanhado pelo crescimento e popularização da internet. Como a revolução causada pela internet modificou totalmente a maneira de se comunicar entre as pessoas o uso dela como uma forma de divulgar as ideias de 
grupos e movimentos sociais foi logo iniciado. A partir daí, o ativismo digital passou a ser uma importante forma de atuação e divulgação das populações excluídas e já tem mostrado importantes resultados, como o Fórum Social Mundial (FSM), que reuniu ativistas de todo o mundo e teve a internet como principal meio de comunicação e divulgação. Com isso o ciberativismo não tem se restringido a uma prática exclusivamente virtual, mas vem se expandindo para o ativismo real, através da mobilização de passeatas, abaixo assinados, petições e atos de vandalismo e protestos em geral. É inegável o alcance da internet como uma importante ferramenta política, e os vários grupos e movimentos se deram conta disso e passaram a usar a rede global como um novo método de organização, com o objetivo de criar e manter o ativismo na internet,

Alguns governos, entre eles, o Irã, Coreia do Norte, Mianmar, República Popular da China e da Arábia Saudita, restringem o que as pessoas em seus países podem acessar, especialmente conteúdos políticos e religiosos. Tal restrição visa abafar o poder da sociedade civil interconectada que cresce cada vez mais em todo o planeta. Um caso célebre e recente (acontecido no ano de 2009) foi a série de protestos virtuais (que desencadearam protestos presenciais) ocasionados pelas fraudes na eleição para presidente da República no Irã e divulgadas pela Rede Mundial de Computadores. Foi por meio do Twitter, do Facebook e outras Redes sociais que a população iraniana pode trocar informações com outros países, já que os veículos tradicionais de mídia sofriam restrições para fazer suas coberturas jornalísticas (Fonseca, 2009).

Estes acontecimentos demonstram a força que tais mídias alternativas têm fornecido aos movimentos. Na introdução desse trabalho foi lembrado que os acontecimentos recentes, no Brasil tiveram início justamente nas redes sociais por meio do compartilhamento de inúmeros abaixo-assinados, petições, convocações de assembleias, partilha de análises críticas e de informações não divulgadas nas grandes mídias. Tudo isso possibilitou que houvesse um retorno dos movimentos às ruas e uma maior atenção por parte da população para os movimentos no sentido de promover uma descriminalização. Apesar de a grande mídia apontar para as "violências" promovidas nesses protestos, com argumentos de "depredação ao patrimônio público", "restauração da ordem", mostraram intensamente os movimentos pelo olhar criminalizante.

\section{Considerações Finais}

Percebeu-se que durante as análises de três séries, havia uma atenção para certa regularidade discursiva. A mídia e a criminalização/judicialização combinadas com a repressão policial se destacam como principais elementos desse processo maior que identifica as práticas dos movimentos sociais, assim como os seus integrantes, às práticas criminosas. Abordou-se que essas práticas se relacionam a uma tecnologia de governo presente nas sociedades modernas que inserem a vida dentro do processo político, ou como denomina Foucault, o biopoder. Esse, ao instituir uma sociedade de normalização, se preocupa em disciplinar os corpos e regulamentar a população, circunscrevendo aqueles que devem viver daqueles que devem morrer. É nesse entremeio que aparece o racismo como elemento que vai promover um corte dentro da sociedade daquelas "raças" que devem permanecer vivas daquelas classificadas enquanto "descartáveis", que podem ou até mesmo deveriam ser extintas. Essa lógica aparece ainda hoje em discursos eugênicos e higienistas que visam provocar uma assepsia social, voltada a uma limpeza dos imundos, dos sujos, daqueles que abalam a ordem social vigente.

A desobediência civil promovida pela maioria dos movimentos e lutas populares ainda provoca medo naqueles que temem a 
ruptura de uma ordem social que há tempos se mostra doente e que, apesar dos vários discursos de igualdade, não consegue promover uma justiça social e uma democracia participativa que não se ampare na tutela e no autoritarismo. No entanto, a articulação promovida por esses grupos vem se tornando cada vez mais forte e intensa. E, como foi apresentado na análise há outra regularidade que se destaca, sendo a própria resistência promovida por esses movimentos, como aponta Foucault (1999/2012): o exercício das relações de poder é da ordem da batalha, do confronto, em que vários campos de força se encontram na luta por novos efeitos de verdade, novas formas de ser, por novas possibilidades de existência. Os movimentos sociais têm se inserido nessa batalha justamente na busca da promoção de novas formas de fazer política, que sejam menos autoritárias e tuteladoras e mais produtoras de liberdade e de relações diagonais.

A análise das dissertações aponta para algumas práticas voltadas contra os movimentos que o inserem em um processo denominado de criminalização. Como foi visto, o número de cinco dissertações aponta para uma escassa produção acadêmica sobre esse processo. No entanto, esse número indica e sinaliza algo. Considera-se que esse número reduzido de produções acerca dessa temática se insere no próprio processo de criminalização investigado. Não falar ou pouco falar significa que a sociedade insiste em calar-se diante de um processo crucial para o exercício da cidadania e da democracia brasileira. Além dessa contribuição, é possível entender que esse trabalho possibilita pensar a partir de estratégias específicas de luta contra a criminalização. $\mathrm{O}$ estudo dos dispositivos midiáticos, por exemplo, se torna fundamental para se entender como as práticas discursivas e não discursivas circulam dentro de jornais, revistas, rádio, televisão e outros meios e ajudam a promover uma "imagem" dos movimentos como atrelados à baderna, à desordem, ao vandalismo, entre outras qualificações que tentam deslegitimar as pautas e lutas desses movimentos. Além disso e, sobretudo, é preciso pensar a mídia como um equipamento que:

não nos indica somente o que pensar, o que sentir, como agir, mas principalmente nos orienta sobre o que pensar, sobre o que sentir. Assim, a mídia nos coloca certos temas e nos faz crer que estes é que são os problemas importantes sobre os quais devemos pensar e nos posicionar. Através da ininterrupta construção de modelos de unidade, de racionalidade, de legitimidade, de justiça, de beleza, de cientificidade os meios de comunicação de massa produzem formas de existir que nos indicam como nos relacionar; enfim, como ser e viver dentro de um permanente processo de modelização. (Coimbra, 2001, p. 2).

Nesse sentido, é importante realizar novos estudos acerca da mídia, não apenas que problematizem e discutam os regimes de verdade que esses dispositivos colocam em funcionamento, mas para destacar as próprias mídias alternativas que tem provocado resistências a essa estrutura dominante dentro de uma Comunicação Social Brasileira controlada por pequenos grupos. Isso é uma alternativa para repensar a própria redemocratização da Comunicação no Brasil.

Outro ponto a se destacar dentro do estudo são as práticas de criminalização e judicialização que inscreve os movimentos dentro das malhas da justiça, imputando crimes a essas lutas e a determinados segmentos marginalizados e excluídos da sociedade. Entendemos que isso faz parte de um contexto neoliberal que instituiu dentro de uma sociedade "globalizada" o crescimento de um Estado Penal em detrimento de um Estado Social típico de uma sociedade baseada no Welfare State (Wacquant, 2003). Por essa razão, que nos propomos pensar esse contexto a partir da noção de biopoder colocada por Foucault (1999) quando pensa as tecnologias de governo que usa a normalização para 
disciplinar e normalizar os corpos e a população e que permite aparecer um racismo que "condena" determinados grupos dentro de uma sociedade à morte. Com isso, espera-se ter contribuído e fomentado novas discussões acerca dos movimentos sociais e das práticas direcionadas a eles e que tentam de diversas maneiras calar-lhes. O processo, como foi descrito, é complexo e permeado por inúmeras lutas, mais precisamente, microlutas, que fazem com que o cotidiano seja extremamente importante para pensar novas formas de se sujeitar politicamente e eticamente na busca por maior autonomia e liberdade e componham novas formas de ser e existir.

\section{Referências}

Avritzer, L. (2013). Impasses da democracia no Brasil. Sapere Aude, 7(14), 872-880.

Recuperado de

http://periodicos.pucminas.br/index.php/Saper eAude/article/view/12217

Benford, R. D. (1997). An insider's critique of the social movement framing perspective. Sociological Inquiry, 67(4), 409-430. doi: 10.1111/j.1475-682X.1997.tb00445.x

Benford, R. D., \& Snow, D. A. (2000).

Framing Processes and Social Movements: an Overview and Assessment. Annual Review of Sociology, 26, 611-639. doi:

10.1146/annurev.soc.26.1.611

Carvalho, J. (2013). Cidadania no Brasil: o longo caminho (16 $6^{\mathrm{a}}$ ed.). Rio de Janeiro:

Civilização Brasileira.

Castro, F. (2012). Comunicação, Poder e

Democracia. Labor Edições.

Certeau, M. (1979). A operação histórica. In J. Le Goff, \& P. Nora (Orgs.), História: Novos Problemas ( $2^{\mathrm{a}}$ ed.). Rio de Janeiro: Francisco Alves.

Chauí, M. (2000). Brasil: mito fundador e sociedade autoritária. São Paulo: Perseu Abramo.

Chauí, M. (1996). Conformismo e Resistência: aspectos da cultura popular no Brasil ( $6^{\mathrm{a}} \mathrm{ed}$.).

São Paulo: Brasiliense.

Coimbra, C. (2001). Mídia e produção de modos de existência. Psicologia: Teoria e Pesquisa, 17(1), 1-4. doi: 10.1590/S010237722001000100002

Coimbra, C., Lobo, L., \& Nascimento, M. (2008). Por uma invenção ética para os Direitos HumanosFor an ethical invention for Human Rights. Psicologia Clínica, 20(2), 89102. doi: 10.1590/S0103-56652008000200007 Diani, M. (1992). The Concept of Social Movement. The Sociological Review, 40(1),
1-25. doi: $10.1111 / \mathrm{j} .1467-$

954X.1992.tb02943.x

Diani, M. (1997). Social movements and social capital: a network perspective on movement outcomes. Mobilization, 2(2), 127147. Recuperado de https://mobilizationjournal.org/doi/abs/10.178 13/maiq.2.2.w6087622383h4341

Fonseca, L. M. (2009). Ciberativismo e MST: o MST sobre a reforma agrária na nova esfera pública interconectada. $116 \mathrm{f}$. Dissertação (Mestrado em Comunicação) - Universidade Federal da Paraíba, João Pessoa.

Foucault, M. (1999). Em defesa da Sociedade: Curso no Collége de France (1975-1976, 3. ed.). São Paulo: Martins Fontes.

Foucault, M. (2012). Nietzsche, a genealogia e a história. In M. Foucault. Microfísica do Poder (25 ed.). São Paulo: Graal.

Foucault, M. (2010). O Sujeito e o Poder. In H. Dreyfus, \& P. Rabinow. Michel Foucault. Uma trajetória filosófica: para além do estruturalismo e da hermenêutica. Rio de Janeiro: Forense Universitária.

Guareschi, P. (2006). Mídia e Cidadania. Conexão-Comunicação e Cultura (UCS), 5(9), 27-40. Recuperado de http://www.ucs.br/etc/revistas/index.php/cone xao/article/view/202

Guattari, F., \& Rolnik, S. (2005). Cultura um conceito reacionário. In F. Guattari, \& S.

Rolnik. Micropolitica: cartografias do desejo (7 $7^{\mathrm{a}}$ ed.). Petrópolis, RJ: Vozes.

Gohn, M. (2001). História dos Movimentos e Lutas Sociais: A construção da cidadania dos brasileiros. São Paulo: Edições Loyola.

Gohn, M. (2010). Movimentos sociais e redes de mobilizações civis no Brasil contemporâneo. Petrópolis, RJ: Vozes. 
Gohn, M. (2012). Novas Teorias dos Movimentos Sociais (4a Ed.). São Paulo: Edições Loyola. Harvey, D., Teles, E., Sader, E., Alves, G., Carneiro, H. S., Wallerstien, I.,... Safatle, V. (2012). Occupy: movimentos de protesto que tomaram as ruas. São Paulo: Boitempo: Carta Maior.

Leão, M. A. S. (2008). Defensores de direitos humanos. In Centro de Estudos e Defesa do Negro no Estado do Pará (org.), Em Defesa da vida: a realidade dos/as defensores/as de direitos humanos sob situação de risco e ameaça no Estado do Pará (pp. 97-177). Belém: CEDENPA.
Lemos, F. C.S.; Cardoso, H. R. Jr. (2008). A genealogia em Foucault: uma trajetoria. Psicologia \& Sociedade, 21(3), 353-357. doi: 10.1590/S0102-71822009000300008 Lima, A. C. S. (2015). Sobre Tutela e Participação: Povos Indigenas e Formas de Governo no Brasil, Séculos XX/XXI. Mana, 21(2), 425-457. doi: 10.1590/0104$93132015 \mathrm{v} 21 \mathrm{n} 2 \mathrm{p} 425$

Sorj, B. (2004). A democracia inesperada: cidadania, direitos humanos e desigualdade social. Rio de Janeiro: Zahar.

Wacquant, L. (2003). Punir os pobres: a nova gestão da miséria nos Estados Unidos (2 $2^{\mathrm{a}} \mathrm{ed}$.). Rio de Janeiro: Revan.

\section{Dados sobre os autores:}

- Flávia Cristina Silveira Lemos: Graduada em psicologia pela UNESP, Mestre em Psicologia Social pela UNESP, Doutora em História pela UNESP, Pós-Doutora em Psicologia pela UFF. Bolsista de Produtividade em Pesquisa CNPQ-PQ2. Professora associada II de Psicologia Social da UFPA.

- Igor do Carmo Santos: Graduado em Psicologia pela UFPA, Mestre em Psicologia pela UFPA, Doutorando em Psicologia pela UFPA. 